\title{
Physiogenomic comparison of human fat loss in response to diets
} restrictive of carbohydrate or fat

\author{
Richard L Seip*1,2, Jeff S Volek ${ }^{3}$, Andreas Windemuth11, Mohan Kocherla1, \\ Maria Luz Fernandez ${ }^{4}$, William J Kraemer ${ }^{3}$ and Gualberto Ruaño ${ }^{1}$
}

\author{
Address: ${ }^{1}$ Genomas, Inc., 67 Jefferson St, Hartford, Connecticut, USA, ${ }^{2}$ Department of Cardiology, Hartford Hospital, Hartford, Connecticut, USA, \\ ${ }^{3}$ Department of Kinesiology, University of Connecticut, Storrs, Connecticut, USA and ${ }^{4}$ Department of Nutritional Sciences, University of \\ Connecticut, Storrs, Connecticut, USA \\ Email: Richard L Seip* - rseip@harthosp.org; Jeff S Volek - jeff.volek@uconn.edu; Andreas Windemuth - a.windemuth@genomas.net; \\ Mohan Kocherla - m.kocherla@genomas.net; Maria Luz Fernandez - maria-luz.fernandez@uconn.edu; \\ William J Kraemer - william.kraemer@uconn.edu; Gualberto Ruaño - g.ruano@genomas.net \\ * Corresponding author
}

Published: 6 February 2008

Nutrition \& Metabolism 2008, 5:4 doi:10.1/86/1743-7075-5-4
Received: 12 August 2007

Accepted: 6 February 2008

This article is available from: http://www.nutritionandmetabolism.com/content/5/l/4

(C) 2008 Seip et al; licensee BioMed Central Ltd.

This is an Open Access article distributed under the terms of the Creative Commons Attribution License (http://creativecommons.org/licenses/by/2.0), which permits unrestricted use, distribution, and reproduction in any medium, provided the original work is properly cited.

\begin{abstract}
Background: Genetic factors that predict responses to diet may ultimately be used to individualize dietary recommendations. We used physiogenomics to explore associations among polymorphisms in candidate genes and changes in relative body fat $(\Delta \% \mathrm{BF})$ to low fat and low carbohydrate diets.

Methods: We assessed $\triangle \% \mathrm{BF}$ using dual energy $\mathrm{X}$-ray absorptiometry (DXA) in 93 healthy adults who consumed a low carbohydrate diet (carbohydrate $~ 12 \%$ total energy) (LC diet) and in 70, a low fat diet (fat $\sim 25 \%$ total energy) (LF diet). Fifty-three single nucleotide polymorphisms (SNPs) selected from 28 candidate genes involved in food intake, energy homeostasis, and adipocyte regulation were ranked according to probability of association with the change in \% $\mathrm{BF}$ using multiple linear regression.

Results: Dieting reduced \%BF by $3.0 \pm 2.6 \%$ (absolute units) for $L C$ and $1.9 \pm 1.6 \%$ for LF ( $<$ 0.01 ). SNPs in nine genes were significantly associated with $\triangle \% \mathrm{BF}$, with four significant after correction for multiple statistical testing: $r s 322695$ near the retinoic acid receptor beta (RARB) ( $P$ $<0.005)$, rs 2838549 in the hepatic phosphofructokinase (PFKL), and rs 3100722 in the histamine $\mathrm{N}$ methyl transferase $(H N M T)$ genes (both $p<0.041$ ) due to LF; and the rs5950584 SNP in the angiotensin receptor Type II (AGTR2) gene due to LC $(p<0.02 \mathrm{I})$.

Conclusion: Fat loss under LC and LF diet regimes appears to have distinct mechanisms, with PFKL and HNMT and RARB involved in fat restriction; and AGTR2 involved in carbohydrate restriction. These discoveries could provide clues to important physiologic mechanisms underlying the $\Delta \% \mathrm{BF}$ to low carbohydrate and low fat diets.
\end{abstract}




\section{Introduction}

Dietary modification remains a logical and fundamental approach to the treatment of obesity. Achieving success may depend on the diet chosen [1-4] and on innate and genetically inherited metabolic characteristics [5]. Ideally, a weight loss diet regimen should decrease excess adipose tissue mass, including the more important visceral fat, and preserve lean tissue. While weight loss occurs with any dietary strategy that restricts energy intake, it is clear that macronutrient composition has a role in determining adipose tissue and lean body mass responses [6]. In particular, changes in dietary carbohydrate affect substrate metabolism through responses of hormones such as insulin [7] that clearly induce macronutrient-dependent expression of genes $[8,9]$. Further, there are interindividual differences in metabolic processing of both carbohydrate [10] and fat [11,12] that have been implicated in obesity. In the present study, we compared the genetic variability associated with relative fat loss induced by energy restricted diets that varied in carbohydrate content. Such knowledge may ultimately lead to the development of DNA guided dietary recommendations.

The genes that influence the adipose tissue and lean body (skeletal muscle + bone) mass compartments alone or in response to dietary intervention remain uncharacterized $[13,14]$. Sorenson et al. [15] examined 42 SNPs in 26 candidate genes hypothesized to modulate obesity but found none to be predictive of the change in body mass index (BMI) induced by dietary restriction of either carbohydrate or fat. Although commonly used, BMI is not a precise surrogate index of adiposity. Its use as a phenotype may make genetic associations with a change in adiposity, difficult to discern.

In order to simultaneously assess relationships between many gene variants and the phenotype of relative body fat, the present study employed physiogenomics [16], a medical application of sensitivity analysis and systems engineering. Sensitivity analysis is the study of the relationship between input and output from a system as determined by system components. Physiogenomics utilizes the genes as the components of the system. The gene variability, measured by single nucleotide polymorphisms (SNPs), is correlated to physiological responses, the output, of a diversely responsive human population. Physiogenomics determines how the SNP frequency varies among individuals similarly responding to the input over the entire range of the response distribution. We have previously utilized physiogenomics to identify genes relevant to dietary weight reduction [5] and drug-induced side effects [17-19].

The present study succeeds a previous physiogenomic study which found that the total body weight loss response to carbohydrate restriction was associated with variants in gastric lipase (LIPF), hepatic glycogen synthase (GYS2), cholesteryl ester transfer protein (CETP) and galanin $(G A L)$ genes [5]. Here we extend that study to compare carbohydrate restriction to fat restriction, using the change in relative fat measured by dual energy $\mathrm{X}$ ray absorptiometry (DXA), an accurate method to assess percent fat $[20,21]$, as a phenotype. We hypothesized that genes representative of food intake, energy homeostasis, and adipocyte regulation may explain the variability in the change in percent body fat accomplished through restriction of fat or carbohydrate.

\section{Methods \\ Subjects and study design}

The subjects included 93 adults who participated in very low carbohydrate (LC) [1,22-25] and 70 who participated in low fat (LF) dietary studies $[1,22]$ designed to examine the effects on weight loss, body composition, and other metabolic responses related to cardiovascular disease in the Human Performance Laboratory at the University of Connecticut (Table 1). The subjects were free of diabetes, cardiovascular, respiratory, gastrointestinal, thyroid and other metabolic disease. They were weight stable $( \pm 2 \mathrm{~kg}$ ) the month prior to starting the study. Subjects were not allowed to use nutritional supplements (except a daily multi-vitamin/mineral), or take medications to control blood lipids or glucose. The majority of subjects were sedentary and all were instructed to maintain the same level of physical activity throughout the study. The LC diet intervention was 12 weeks for the majority of subjects, but in some cases the duration was shorter (4-6 wk). Before and after LC and LF, body mass was determined in the morning after an overnight fast on a calibrated digital scale with subjects in light clothing and not wearing shoes. All subjects signed an informed consent document approved by the University of Connecticut Institutional Review Board.

\section{Dietary protocols}

Low carbohydrate (LC)

The LC diet intervention has been described previously [5]. Subjects were free-living with the main goal to restrict carbohydrate $(\mathrm{CHO})$ to a level that induced a small level of ketosis. There were no restrictions on the type of fat from saturated and unsaturated sources or cholesterol levels. Foods commonly consumed were beef (e.g., hamburger, steak), poultry (e.g., chicken, turkey), fish, vegetable oils, various nuts/seeds and peanut butter, moderate amounts of vegetables, salads with low CHO dressing, moderate amounts of cheese, eggs, protein drinks, and water or low $\mathrm{CHO}$ diet drinks. To ensure appropriate $\mathrm{CHO}$ restriction, subjects monitored their level of ketosis daily using urine reagent strips that produce a relative color change in the presence of one of the primary 
Table I: Demographic characteristics of the subjects in the low fat (LF) and low carbohydrate (LC) diet groups.

\begin{tabular}{|c|c|c|c|c|c|c|c|}
\hline \multirow[b]{2}{*}{ Variable } & \multirow[b]{2}{*}{ Value } & \multicolumn{3}{|c|}{ Low Fat } & \multicolumn{3}{|c|}{ Low Carbohydrate } \\
\hline & & Subjects & $\begin{array}{l}\text { Baseline \% } \\
\text { Body fat }\end{array}$ & $\begin{array}{c}\text { Mean change, \% Body } \\
\text { Fat [absolute \%] }\end{array}$ & Subjects & $\begin{array}{l}\text { Baseline \% } \\
\text { Body fat }\end{array}$ & $\begin{array}{c}\text { Mean change, \% Body } \\
\text { Fat [absolute \%] }\end{array}$ \\
\hline All & All & 70 & 35.5 & -2.02 & 93 & 34.6 & -2.97 \\
\hline \multirow[t]{2}{*}{ Gender } & Female & 33 & 37.6 & -1.49 & 31 & 38.0 & -1.27 \\
\hline & Male & 37 & 33.7 & -2.43 & 62 & 32.9 & -3.80 \\
\hline \multirow[t]{6}{*}{ Age } & $<20$ & 8 & 34.4 & -3.00 & 7 & 34.8 & -4.70 \\
\hline & $20-30$ & 26 & 32.2 & -1.56 & 36 & 33.4 & -2.36 \\
\hline & $30-40$ & 17 & 39.6 & -2.32 & 20 & 37.2 & -2.81 \\
\hline & $40-50$ & 13 & 33.9 & -2.60 & 21 & 35.0 & -2.72 \\
\hline & $50-60$ & 7 & 41.6 & -0.85 & 6 & 32.6 & -4.93 \\
\hline & $60-70$ & 0 & - & - & 3 & 32.5 & -6.00 \\
\hline \multirow[t]{4}{*}{ Heritage } & African Amer & 4 & 37.9 & -1.63 & 5 & 36.7 & -2.82 \\
\hline & Asian & $\mathrm{I}$ & 36.5 & -3.08 & 4 & 36.2 & -3.34 \\
\hline & Caucasian & 63 & 35.4 & -2.01 & 81 & 34.5 & -2.50 \\
\hline & Hispanic & 2 & 32.3 & -0.99 & 3 & 34.7 & -2.16 \\
\hline
\end{tabular}

ketones, acetoacetic acid. Blood ketones were also checked during the diets. On this basis, all subjects were in ketosis for the majority of the experimental period. The actual mean nutrient breakdown of the diets as a percentage of total energy was obtained from at least 15 days of weighed food records across the various studies from which subjects were pooled.

\section{Low fat (LF)}

The LF diet was designed to provide $<10 \%$ of total calories from saturated fat and $<300 \mathrm{mg}$ cholesterol/day [1]. Foods encouraged included whole grains (breads, cereals, and pastas), fruit and fruit juices, vegetables, vegetable oils, low-fat dairy and lean meat products. Standard diabetic exchange lists were used to foster a macronutrient balance of protein ( $20 \%$ energy), fat ( $25 \%$ energy), and carbohydrate ( $55 \%$ of energy). All subjects received extensive initial verbal and written instructions and weekly follow-up dietetic education. Subjects received thorough instructions for completing detailed weighed food records during baseline and various phases of the diet that were subsequently analyzed using regularly updated nutrient analysis software (NUTRITIONIST $\mathrm{PRO}^{\mathrm{TM}}$, Version 1.5, First Databank Inc, The Hearst Corporation, San Bruno, CA). The actual mean nutrient breakdown of the diets as a percentage of total energy was obtained from at least 15 days of weighed food records.

\section{Percent body fat measurement}

Whole body composition was assessed using DXA (Prodigy $^{\mathrm{rm}}$, Lunar Corporation, Madison, WI). Analyses were performed by the same technician (blinded as to dietary intervention) using commercial software (enCORE version 6.00.270). Percent body fat was calculated as soft tissue fat mass divided by the sum of soft tissue fat mass, soft tissue lean body mass, and bone mineral content. Coeffi- cients of variation for lean body mass, fat mass, and bone mineral content on repeat scans with repositioning on a group of men and women in our laboratory were $0.4,1.4$, and $0.6 \%$, respectively.

\section{Selection of candidate genes}

To identify genes involved in physiological responses to carbohydrate versus fat ingestion, we canvassed physiological pathways and biological processes relevant to the regulation of adiposity, including but not limited to eating behavior, digestion and absorption, hormonal signaling in the prandial and postprandial period, the regulation of fuel distribution and processing, and the control of adipocyte size and proliferation. From these categories, we selected 28 genes to represent three categories: food intake, energy homeostasis, and adipocyte regulation. Table 2 provides summary information relevant to the genes and SNPs. The role for each gene is described below.

\section{Food intake}

The GAL and GHRL genes, expressed in the hypothalamus [26] and stomach [27], respectively, encode for the orexigens galanin and ghrelin, respectively [26,27]. HNMT encodes for histamine N-methyl transferase, which inactivates histamine and is widely expressed in the stomach, thymus, lung, spleen, kidney, and particularly the brain [28]. LIPF encodes for gastric lipase, which hydrolyzes triglycerides, freeing fatty acids for intestinal uptake [29]. The PYY gene encodes for peptide YY, a gut endocrine factor that circulates after meals [30]. NPY encodes for neuropeptide $\mathrm{Y}$, an abundant brain and autonomic neurotransmitter [31] and potent orexigen [32]. NPY5R encodes for one of five neuropeptide $Y$ receptors studied in relation to energy balance [33]. The LEPR gene encodes for the leptin receptor, believed critical in the central reg- 
Table 2: Genes and SNPs analyzed for associations with percent body fat change profiles for LF and LC groups.

\begin{tabular}{|c|c|c|c|c|c|}
\hline Area & Pathway & Gene & Symbol & SNP & Type \\
\hline \multirow[t]{16}{*}{ Food Intake } & Neural & galanin & GAL & rs694066 & intron I \\
\hline & & leptin receptor & LEPR & rs7602 & intron I (3' UTR on another gene) \\
\hline & & & & rs II7I276 & intron I (untranslated) \\
\hline & & & & rs8179183 & exon $12, \mathrm{~N} 656 \mathrm{~K}$ \\
\hline & & melanocortin 3 receptor & MC3R & rs6024725 & $\sim 10 \mathrm{~kb}$ upstream \\
\hline & & neuropeptide $Y$ & NPY & rs|46827| & intron I \\
\hline & & neuropeptide $Y$ receptor $Y 5$ & NPY5R & rsll 00494 & intron 3 \\
\hline & & & & rs6837793 & $\sim 9 \mathrm{~kb}$ upstream \\
\hline & Neural/Gut & histamine $\mathrm{N}$-methyltransferase & HNMT & rs 1801105 & exon $4,1105 T$ \\
\hline & & & & rs12691940 & intron 2 \\
\hline & Gut & apolipoprotein A-IV & APOA4 & rs675 & T367S, exon 3 \\
\hline & & & & rs5092 & exon 2, T29T \\
\hline & & ghrelin precursor & GHRL & rs 26312 & $\sim 1 \mathrm{~kb}$ upstream \\
\hline & & lipase, gastric & LIPF & rs814628 & exon $4, \mathrm{AI} 6 \mathrm{IT}$ \\
\hline & & peptide YY & PYY & rsI058046 & exon 2, R72T \\
\hline & & & & rs $23 \mid 460$ & $\sim 1.8$ kb upstream \\
\hline \multirow[t]{21}{*}{ Energy Homeostasis } & Metabolic Enzyme & glycogen synthase kinase 3 beta & GSK3B & rs4688046 & intron 3 \\
\hline & & & & rs334555 & intron I \\
\hline & & & & rs10934502 & intron 2 \\
\hline & & glycogen synthase I (muscle) & GYSI & rs2287754 & 5' UTR \\
\hline & & glycogen synthase 2 (liver) & GYS2 & rs 1478290 & upstream, $\sim 3.5 \mathrm{~Kb}$ \\
\hline & & & & rs2306179 & intron 5 \\
\hline & & & & rs10505873 & intron 3 \\
\hline & & phosphofructokinase, liver & PFKL & rs2838549 & intron 8 \\
\hline & & phosphofructokinase, muscle & PFKM & rs2269935 & $\sim 700$ bp upstream \\
\hline & & pyruvate kinase, liver and RBC & PKLR & rs3762272 & intron 2 \\
\hline & & pyruvate kinase, muscle & PKM2 & rs2856929 & intron 7 (MT) \\
\hline & Nuclear Signaling & retinoic acid receptor, alpha & RARA & rs4890109 & intron 3 \\
\hline & & & & rs9904270 & $\sim 7.5$ kb upstream \\
\hline & & retinoic acid receptor, beta & RARB & rs2033447 & intron 2 (MT) \\
\hline & & & & rs I 290443 & intron 3 (MT) \\
\hline & & & & rs322695 & $\sim 100 \mathrm{~kb}$ upstream \\
\hline & & retinoic acid receptor, gamma & RARG & rs10082776 & intron 2 (untranslated) \\
\hline & & retinoid $X$ receptor, alpha & $R \times R A$ & rs4917348 & $\sim 100 \mathrm{kbp}$ upstream \\
\hline & & & & rs3750546 & $\sim 100 \mathrm{~kb}$ upstream \\
\hline & & & & rs3118536 & intron 3 \\
\hline & & retinoid $X$ receptor, gamma & $R X R G$ & rs|57864 & intron 4 \\
\hline \multirow[t]{15}{*}{ Adipocyte Regulation } & Adipokine-related & adiponectin receptor 2 & ADIPOR2 & rs2058II2 & intron I (untranslated?) \\
\hline & & & & rs7975375 & intron I (untranslated?) \\
\hline & & angiotensin II receptor, type I & AGTRI & rs|2695902 & intron 3 \\
\hline & & & & rs 931490 & intron 2 (untranslated?), (MT) \\
\hline & & angiotensin II receptor, type 2 & AGTR2 & rs5950584 & $\sim 4.5$ kb upstream \\
\hline & & resistin & RETN & rs3219177 & intron I \\
\hline & Lipid Metabolic & apolipoprotein E & APOE & rs7412 & exon $3, \mathrm{CI} 76 \mathrm{R}, * 2->* 3$ \\
\hline & & & & rs429358 & exon $3, \mathrm{R} / 30 \mathrm{C}, * 4->* 3$ \\
\hline & & & & rs405509 & $\sim 200$ bp upstream \\
\hline & & & & rs43940I & $\sim 1.5 \mathrm{kbp}$ downstream \\
\hline & & & & rs446037 & $\sim 1.5$ kbp upstream \\
\hline & & cholesteryl ester transfer protein, plasma & CETP & rs5883 & exon 9, F287F \\
\hline & & & & rsI532624 & intron 7 \\
\hline & & & & rs376426I & $\sim 2.6 \mathrm{~kb}$ upstream \\
\hline & & & & rs5880 & nonsynonymous, $\mathrm{P} 390 \mathrm{~A}$ \\
\hline
\end{tabular}

ulation of energy homeostasis [34]. MC3R encodes for the melanocortin receptor 3 , which regulates energy homeostasis in response to neuropeptides secreted by pro-opiomelanocortin and agouti related peptide releasing neurons [35]. APOA4 encodes for apolipoprotein A-IV, is expressed by intestinal cells in response to fat absorption [36], and has a hypothesized, centrally-mediated role in the regulation of energy intake [36]. 


\section{Energy homeostasis}

GSK3B encodes for glycogen synthase kinase $3 \beta-9$, which inactivates glycogen synthase by phosphorylation [37]. Glycogen synthase (GYS) catalyzes the rate-limiting step in glycogen synthesis. GYS1 and GYS2 are expressed liver and muscle, respectively. The PFKL and PFKM genes encode the liver [38] and muscle [39] isoforms of phosphofructokinase, respectively. Phosphofructokinase is the key regulatory enzyme for glycolysis. PKLR and PKM2 encode for liver and muscle isoforms of pyruvate kinase, an enzyme of glycolysis and gluconeogenesis [37]. The RARA, RARB, and RARG; and RXRA and RXRG genes are members of the nuclear receptor superfamily. The $R A R$ and $R X R$ gene products participate in the regulation of energy balance at a neural level [40] and their expression in hepatic and adipose tissues is diet-responsive [41,42].

\section{Adipose regulation}

The ACGT1 and AGTR2 genes express angiotensin II receptors type I and II. Both play roles in adipocyte regulation and cellularity [43]. The ADIPOR2 gene encodes adiponectin receptor type $\mathrm{I}$; muscle expression of this gene plays a role in non-oxidative glycolysis [44]. Apolipoprotein $\mathrm{E}$ and cholesteryl ester protein, encoded by the $A P O E$ and CETP genes, respectively, have widespread roles in lipid metabolism. Both are expressed in adipocytes [45-47] and subject to nutritional regulation $[45,48]$. RSTN encodes for the adipocyte-secreted factor, resistin, which is increased in obesity [49].

\section{Laboratory analysis}

Blood samples were collected from an arm vein into tubes for DNA extraction. The DNA was extracted from $8.5 \mathrm{~mL}$ of whole blood using the PreAnalytiX PAXgene DNA isolation kit (Qiagen Inc, Valencia, CA). For some earlier participants, neither whole blood nor DNA were available, so DNA from lymphocytes remaining in archived serum samples were amplified using the QiaGen REPLI-g Whole Genome Amplification kit. Genotyping was performed using the Illumina BeadArray ${ }^{\mathrm{TM}}$ platform and the GoldenGate $^{\mathrm{TM}}$ assay $[50,51]$. The assay information and observed allele frequencies for the SNPs used in this study are listed in Table 3.

\section{Data analysis}

All statistical analysis was performed using the R Statistics Language and Environment [52-54]. Covariates were analyzed using multiple linear regression, and selected using the stepwise procedure. The change in relative fat mass, $\Delta \% \mathrm{BF}$, was calculated as the difference between post-diet and baseline measurements of \%BF. To test for association with SNP genotypes, the residual of $\Delta \% \mathrm{BF}$ after covariate analysis was tested using linear regression on the SNP genotypes. SNP genotype was coded quantitatively as a numerical variable indicating the number of minor alle- les: 0 for major homozygotes, 1 for heterozygotes, and 2 for minor homozygotes. The F-statistic p-value for the SNP variable was used to evaluate the significance of association. To test the validity of the p-values, we also performed an independent calculation of the p-values using permutation testing. The ranking of the first three SNPs were identical under permutation and F-statistic analyses (data not shown). To account for the multiple testing of 53 SNPs, we calculated adjusted p-values using Benjamini and Hochberg's false discovery rate (FDR) procedure [5557].

\section{LOESS representation}

We use a locally smoothed function of the SNP frequency as it varies with $\Delta \% B F$ to visually represent the nature of an association. LOESS (LOcally wEighted Scatter plot Smooth) is a method to smooth data using a locally weighted linear regression $[58,59]$. At each point in the LOESS curve, a quadratic polynomial is fitted to the data in the vicinity of that point. The data are weighted such that they contribute less if they are further away, according to the tricubic function

$$
w_{i}=\left(1-\left|\frac{x-x_{i}}{d(x)}\right|^{3}\right)^{3},
$$

where $x$ is the abscissa of the point to be estimated, the $x_{i}$ are the data points in the vicinity, and $d(x)$ is the maximum distance of $x$ to the $x_{i}$.

\section{Results \\ Dietary intake}

The intake of total dietary energy at baseline did not differ between groups, nor did absolute amounts of protein, carbohydrate, and fat (Table 4). Relative to total energy intake, the intakes of protein, carbohydrate, and fat energy at baseline for LC and LF, expressed as percent of total energy, were $15.9 \%, 50.2 \%$, and 32.6 ; and $16.6 \%, 47.7 \%$, and $34.9 \%$; respectively.

Dietary intervention decreased mean total energy intake to $1470 \mathrm{kcal}$ in LF and to $1705 \mathrm{kcal} /$ day in LC ( $\mathrm{p}<0.01)$, representing mean changes from baseline of $-32.5 \%$ and 26.5\%, respectively. During intervention, carbohydrate intake averaged $212 \mathrm{~g} /$ day (57\% of total energy) in LF compared to $53 \mathrm{~g} /$ day (12\% of total energy intake) in LC. Protein intake averaged $94 \mathrm{~g} /$ day (19\% of total energy) in LF and $115 \mathrm{~g} /$ day (28\% of total energy) in LC. Fat intake averaged $37 \mathrm{~g} /$ day (23\% of total energy) in LF and $112 \mathrm{~g} /$ day (59\% of total energy) in LC. All between-group differences in macronutrient gram intake were significant $(\mathrm{p}<$ $1^{\mathrm{e}-10}$, Table 4). 
Table 3: Assay DNA sequences for the SNPs analyzed.

\begin{tabular}{|c|c|c|c|c|c|c|c|}
\hline SNP & Gene & Chr & mac & $\min$ & maj & Freq & Sequence Context \\
\hline rs694066 & GAL & 11 & 20 & A & G & 0.09 & TTCTAAGTCCTCTGCCATGCC [A/G]GGAAAGCCTGGGTGCACCCA \\
\hline rs7602 & LEPR & 1 & 29 & A & G & 0.16 & CTTGGAGAGGCAGATAACGCT [A/G]AAGCAGGCCTCTCATGACCC \\
\hline rs II7I 276 & APOA4 & I & 23 & A & G & 0.13 & AGTTTCATGTACATTAAATAT [A/G]AATTTCTTTTGGCTGGAAAT \\
\hline rs8179183 & APOA4 & 1 & 31 & C & G & 0.18 & TAATGGAGATACTATGAAAAA [C/G]GAGAAAAATGTCACTTTACT \\
\hline rs6024725 & MC3R & 20 & 31 & $\mathrm{~T}$ & C & 0.22 & CCTAGAGACATATCTCAGTTA [A/G]GTTTTAGCCTCACCAGTATT \\
\hline rs|46827| & NPY & 7 & 12 & A & G & 0.06 & GACCCTGTAATTTTCAGAAAC [A/G]CACATAGGAGTGGGTGTCTG \\
\hline rsIII00494 & NPY5R & 4 & 10 & A & C & 0.05 & CAGAAAGATGTCATCATCCAG [A/C]ATTGCGTCCACACAGTCAAC \\
\hline rs6837793 & NPY5R & 4 & 18 & A & G & 0.10 & ATGAATTGTCACTCAGAAGAA [A/G]CTTAATAGGCATTAATACTA \\
\hline rs 1801105 & HNMT & 2 & 14 & $\mathrm{~T}$ & C & 0.08 & TTTACGTTCTCGAGGTTCGAT [A/G]TCTTGGCTACAAGCTCTAAA \\
\hline rs 12691940 & HNMT & 2 & 66 & A & G & 0.00 & AATCAACCAAGTGGAAGAAAG [A/G]ATATCAGAGTCTGAAGACAA \\
\hline rs675 & APOA4 & 11 & 32 & $\mathrm{~T}$ & A & 0.16 & GAGAAAGAGAGCCAGGACAAG [A/T]CTCTCTCCCTCCCTGAGCTG \\
\hline rs5092 & APOA4 & 11 & 30 & A & G & 0.16 & CAGTGCTGACCAGGTGGCCAC [A/G]GTGATGTGGGACTACTTCAG \\
\hline rs 26312 & GHRL & 3 & 36 & A & G & 0.15 & GCTGTTGCTGCTCTGGCCTCT [A/G]TGAGCCCCGGGAGTCCGCAG \\
\hline rs814628 & LIPF & 10 & 26 & A & G & 0.14 & ATCGACTTCATTGTAAAGAAA [A/G]CTGGACAGAAGCAGCTACAC \\
\hline rs 1058046 & PYY & 17 & 78 & C & G & 0.38 & GGAAAAGAGACGGCCCGGACA [C/G]GCTTCTTTCCAAAACGTTCT \\
\hline rs 231460 & PYY & 17 & 43 & $\mathrm{~T}$ & C & 0.23 & TGCTCACCCTAGGATGGAGGG [A/G]GCAGTGGGGGCTGGTTAGGA \\
\hline rs4688046 & GSK3B & 3 & 44 & $\mathrm{~T}$ & C & 0.24 & TAGTAAACTATTTCTTCCCAT [A/G]GGAGAAGATGGATTCTTTTC \\
\hline rs334555 & GSK3B & 3 & 24 & C & G & 0.13 & AATTATATCTTATTATTAAAA [C/G]TCTACCAACTCAAAGCTTCC \\
\hline rs 10934502 & GSK3B & 3 & 40 & $\mathrm{~T}$ & C & 0.24 & GCTTCCTTATGTAAAATGTAG [A/G]TATTTCTAAAGTAACGCAAT \\
\hline rs2287754 & GYSI & 19 & 25 & A & G & 0.15 & CGGGAAGCTTGCAAGACGCTC [A/G]GCTTCCTATTGCAAGACCGC \\
\hline rs 1478290 & GYS2 & 12 & 59 & $\mathrm{~T}$ & G & 0.26 & AATGTGGCTGAAGCCAAAAGC [A/C]TAATGAATGAGGGGAAGCCT \\
\hline rs2306I79 & GYS2 & 12 & 52 & A & G & 0.27 & TTTCAGTAGGTTTGCAGGGAA [A/G]CCAACTCAAAGCTATATCTG \\
\hline rs 10505873 & GYS2 & 12 & 67 & $\mathrm{~T}$ & C & 0.49 & TGCTCAGCCTTCTTCAATGAC [A/G]GTGTTTTGCTATTGTCTCTA \\
\hline rs2838549 & PFKL & 21 & 15 & A & G & 0.09 & GGACACTGGTTCCACCTCCGC [A/G]TGGCTGTACAGTGCTGCCGA \\
\hline rs2269935 & PFKM & 12 & 53 & A & C & 0.26 & CGGCAATTAGACTGGCTAGAG [A/C]CACCTCAGTCAGGCTCTCCC \\
\hline rs3762272 & PKLR & 1 & 13 & A & G & 0.06 & AACAAAGATTCTCCTTTCCTC [A/G]TTCACCACTTTCTTGCTGTT \\
\hline rs2856929 & PKM2 & 15 & 39 & A & G & 0.24 & CAGGCTCAGGGTCTAAATTCC [A/G]TATCCTTTCTTCCATACCCT \\
\hline rs4890109 & RARA & 17 & 10 & $\mathrm{~T}$ & G & 0.05 & GGCTGCTCAGGGCCTCGTCCA [A/C]CCCCAGCCTGACAGAGAGCT \\
\hline rs9904270 & RARA & 17 & 29 & $\mathrm{~T}$ & C & 0.15 & GCCTTCCCCTTAGAGAAGAGC [A/G]CCTGCCAGACAAGGGAGAAG \\
\hline rs2033447 & RARB & 3 & 43 & $\mathrm{~T}$ & C & 0.20 & ATGCCGGGTGCTAGAGATACA [A/G]CAGTGAACATGACAAAGTTC \\
\hline rs 1290443 & RARB & 3 & 30 & A & G & 0.15 & AGAAGCTCTTTCATGTTGTCA [A/G]TTTTAGAAATCCAAATCATT \\
\hline rs322695 & RARB & 3 & 29 & A & G & 0.15 & CCTGTAGGATTGTGTTCCTCT [A/G]AAACTGTCCCCTAAATTATG \\
\hline rs2838549 & PFKL & 21 & 51 & A & G & 0.09 & GGACACTGGTTCCACCTCCGC [A/G]TGGCTGTACAGTGCTGCCGA \\
\hline rs|57864 & RXRG & 1 & 17 & $\mathrm{~T}$ & C & 0.10 & ATGATATTGAATTAAAGGAAA [A/G]TGAATGGTCTCAGTCAGAGA \\
\hline rs3118536 & RXRA & 9 & 31 & A & C & 0.14 & CTGCAGGTGCACGGTTTCCTG [A/C]TTGCCCAGGTGTCTCTGAGC \\
\hline rs4917348 & RXRA & 9 & 40 & A & G & 0.21 & GGTGGGGTTAGAGGGGATGGT [A/G]CCTGGCAGTGTGCAGCAGAC \\
\hline rs3750546 & RXRA & 9 & 43 & A & G & 0.20 & CCTGAGGATGAAGGGGCGTCC [A/G]TGGCCAGGCAGCAGTGAGAA \\
\hline rs I57864 & PYY & 1 & 17 & $\mathrm{~T}$ & C & 0.10 & ATGATATTGAATTAAAGGAAA [A/G]TGAATGGTCTCAGTCAGAGA \\
\hline rs 2058112 & ADIPOR2 & 12 & 27 & $\mathrm{~T}$ & C & 0.15 & TCTTCTTGCCCTACATACTTC [A/G]AAAGCCCTTGGAGAAATCCT \\
\hline rs7975375 & ADIPOR2 & 12 & 31 & $\mathrm{~T}$ & $\mathrm{C}$ & 0.17 & CTTTTCACAGGAAAATTTCTT [A/G]GGAGTCTATTGTCACTGTCT \\
\hline rs 12695902 & AGTRI & 3 & 16 & A & G & 0.09 & CATCAGGATTATCAGCATTTA [A/G]GCCAGAGTTGCAAATTAAGT \\
\hline rs931490 & AGTRI & 3 & 23 & A & G & 0.19 & GGCGCCCCCTGGACTTCTGCT [A/G]GAATTTAGATTTAAATAGAT \\
\hline rs5950584 & AGTR2 & $\mathrm{x}$ & 8 & $\mathrm{~T}$ & G & 0.04 & CTATCCTCAAATGCTATATAA [A/C]CCAACTGGTGGAAAAAAATT \\
\hline rs3219177 & RETN & 19 & 31 & $\mathrm{~T}$ & C & 0.15 & CCAGGGATCAGTGAGGTCTCT [A/G]AGACCCTTGGGGAGCTTGCC \\
\hline rs74I2 & APOE & 19 & 18 & $\mathrm{~T}$ & $\mathrm{C}$ & 0.08 & CGGCCTGGTACACTGCCAGGC [A/G]CTTCTGCAGGTCATCGGCAT \\
\hline rs429358 & APOE & 19 & 31 & $\mathrm{~T}$ & C & 0.14 & GGTACTGCACCAGGCGGCCGC [A/G]CACGTCCTCCATGTCCGCGC \\
\hline rs405509 & APOE & 19 & 79 & A & C & 0.00 & GAGGACACCTCGCCCAGTAAT [A/C]CAGACACCCTCCTCCATTCT \\
\hline rs43940I & APOE & 19 & 59 & $\mathrm{~T}$ & $\mathrm{C}$ & 0.34 & GAGAACTGAGGGGGTGGGAGG [A/G]GAAGAGAGTGCCGGCGGCTC \\
\hline rs446037 & APOE & 19 & 5 & A & $\mathrm{C}$ & 0.02 & AGACACAGGTGACCCAACTCC [A/C]ATGGCTGGCCTAGGCCCCTC \\
\hline rs5883 & CETP & 16 & 13 & $\mathrm{~T}$ & C & 0.06 & AGCTACCTTGGCCAGCGAGTG [A/G]AAGACTCGCTCAGAGAACCA \\
\hline rs1532624 & CETP & 16 & 76 & $\mathrm{~T}$ & G & 0.00 & TCTGCCCCTTTGGGCTGCAGC [A/C]TCACAAGCTGTGTGGCGTTG \\
\hline rs3764261 & CETP & 16 & 46 & $\mathrm{~T}$ & G & 0.27 & AGTGAATGAGATAGCAGACAA [A/C]CCAGATGCCTACCGACAGGT \\
\hline rs5880 & CETP & 16 & 15 & C & G & 0.08 & GATATCGTGACTACCGTCCAG [C/G]CCTCCTATTCTAAGAAAAGC \\
\hline
\end{tabular}

Chr: chromosome location of the gene; mac: the number of minor alleles found; maj: sequence of the most common allele, major; min: sequence of the least common allele, minor; Freq: frequency $(0.00-1.00)$ of the minor allele in the study population. 
Table 4: Dietary data at baseline and during LF and LC interventions.

\begin{tabular}{|c|c|c|c|c|c|c|}
\hline \multirow[b]{2}{*}{ Condition } & \multirow[b]{2}{*}{ Group } & \multirow[b]{2}{*}{ Total Energy Intake (Kcal/d) } & \multicolumn{4}{|c|}{ Intake (grams/day) } \\
\hline & & & Protein & Carbohydrate & Fat & Alcohol \\
\hline \multirow[t]{2}{*}{ Baseline } & LF & $2176.3 \pm 518.4$ & $87.3 \pm 23.0$ & $273.2 \pm 65.5$ & $80.9 \pm 29.7$ & $3.5 \pm 6.9$ \\
\hline & LC & $2291.8 \pm 735.9$ & $94.3 \pm 32.2$ & $267.3 \pm 80.5$ & $92.1 \pm 43.6$ & $4.4 \pm 1.1$ \\
\hline \multirow[t]{2}{*}{ Diet } & LF & $1470.0 \pm 348.7 \ddagger$ & $69.2 \pm 19.0 \ddagger$ & $212.1 \pm 59.2 \ddagger$ & $37.3 \pm 12.6 \ddagger$ & $3.1 \pm 4.6$ \\
\hline & $\mathrm{LC}$ & $1705.2 \pm 57.1$ 抽 & $1 \mid 4.9 \pm 32.8 \neq \S$ & $53.2 \pm 42.6 \ddagger \S$ & $1 \mid 1.9 \pm 38.7 \ddagger \S$ & $1.9 \pm 3.3 *$ \\
\hline
\end{tabular}

$t_{p}<0.01$, LC vs. LF, within condition

$\S \mathrm{p}<1 \mathrm{e}^{-10}, \mathrm{LC}$ vs. LF, within condition

$* \mathrm{p}<0.05$, Baseline vs. Diet, within group

$\ddagger p<0.000$ I, Baseline vs. Diet, within group

\section{Body mass and composition}

There were no differences in body size or composition between groups at baseline. With diet intervention, the change in total body, fat, and lean masses were significantly greater in LC (Table 5).

Figure 1 depicts the baseline and changes in \% body fat profiles in the LF and LC study populations. The distributions are approximately normal and the baseline percent body fat levels for LF $(35.4 \pm 7.8 \%)$ and LC $(34.5 \% \pm$ $7.3 \%$ ) were not different between groups. Overall LC induced an absolute decrease in \% body fat of $2.98 \pm$ $2.62 \%$, reflecting losses of $4.8 \mathrm{~kg}$ of fat mass and $1.42 \mathrm{~kg}$ of lean mass, compared to a \% fat decrease of $1.92 \pm$ $1.63 \%$ in $\mathrm{LF}(\mathrm{p}<0.01)$, reflecting losses of $3.18 \mathrm{~kg}$ for fat mass and $0.70 \mathrm{~kg}$ for lean mass. Men outnumbered women in both study groups and had lower baseline \% body fat in both groups (33.7 vs. $37.6 \mathrm{LF}$, and 32.9 vs. 38.0 LC) (Table 1$)$. The change in $\%$ body fat $(\Delta \% \mathrm{BF})$ due to diet was greater for men versus women (Table 5). For physiogenomics analyses, we employed gender as a covariate to account for the difference.

\section{Physiogenomic associations}

Table 6 lists the results of the association tests, comparing LF and LC groups. A single SNP rs322695 in the RARB gene was significantly associated with $\triangle \% \mathrm{BF}$ for both the LF and LC interventions ( $\mathrm{p}<0.0001$ and $\mathrm{p}<0.0121$, respectively). SNPs in the HNMT (rs3100722, p < 0.002) and PFKL genes (rs2838549, p < 0.002) were significant only for the LF group. Conversely, the rs5950584 SNP in the AGTR2 gene was significant only for the LC group ( $\mathrm{p}$ $<0.0001)$. The FDR-corrected p values yield an estimate of the false positive rate. The following SNPs, RARB rs322695, HNMT rs1269140, and PFKL rs2838549 and associations in LF, and the AGTR2 SNP rs5950584 association in LC are clearly significant after the FDR correction ( $\mathrm{p}<0.005, \mathrm{p}<0.041, \mathrm{p}<0.041$, and $\mathrm{p}<0.041$, respectively). All remaining genes showed no significant association in either treatment group, and no gene showed significance for both diet treatments after adjusting for multiple tests.

Figure 2 shows the top three markers (according to $\mathrm{p}$ value) related to LF response. The first panel shows the LOESS curve for SNP rs322695 of the RARB gene. The frequency of the minor allele increases as the $\Delta \% B F$ response to the LF diet becomes less pronounced (i.e., no loss of relative fat mass). The minor allele is completely absent among subjects with the largest decreases in $\% \mathrm{BF}$, and the frequency is $<10 \%$ among subjects whose decrease in $\% \mathrm{BF}$ exceeded $1 \%$. This finding indicates a strong association between the RARB marker and response to LF. Similar patterns are seen for HNMT rs3100722 and PFKL SNP rs2838549. The SNPs, RARB SNP rs322695, HNMT SNP rs3100722, and PFKL SNP rs2838549, are considered "torpid" markers for responsiveness to the LF diet.

Figure 3 shows the top three markers associated with $\triangle \% \mathrm{BF}$ through LC. The first panel in Figure 3 shows the LOESS curve for SNP rs5950584 of the AGTR2 gene. The frequency of the minor allele is $30 \%$ in the $\Delta \% \mathrm{BF}$ range

Table 5: Baseline and change in total body mass and composition for LC and LF.

\begin{tabular}{ccccccc}
\hline & \multicolumn{3}{c}{ Baseline } & & \multicolumn{3}{c}{ Change } \\
\cline { 2 - 8 } Group & Total Body Mass & Fat Mass & Lean Mass & Total Body Mass & Fat Mass & Lean Mass \\
\hline LF & $89.5 \pm 21.2$ & $32.2 \pm 11.2$ & $54.4 \pm 13.1$ & $-4.0 \pm 2.9$ & $-3.2 \pm 2.2$ & $-0.7 \pm 1.9$ \\
LC & $91.0 \pm 20.0$ & $31.8 \pm 10.3$ & $56.3 \pm 12.8$ & $-6.5 \pm 4.1 \neq$ & $-4.8 \pm 3.0 \ddagger$ & $-1.4 \pm 2.6^{*}$
\end{tabular}

\footnotetext{
$* \mathrm{p}<0.05, \mathrm{LC}$ vs. LF

$\ddagger \mathrm{p}<0.000 \mathrm{I}, \mathrm{LC}$ vs. LF
} 

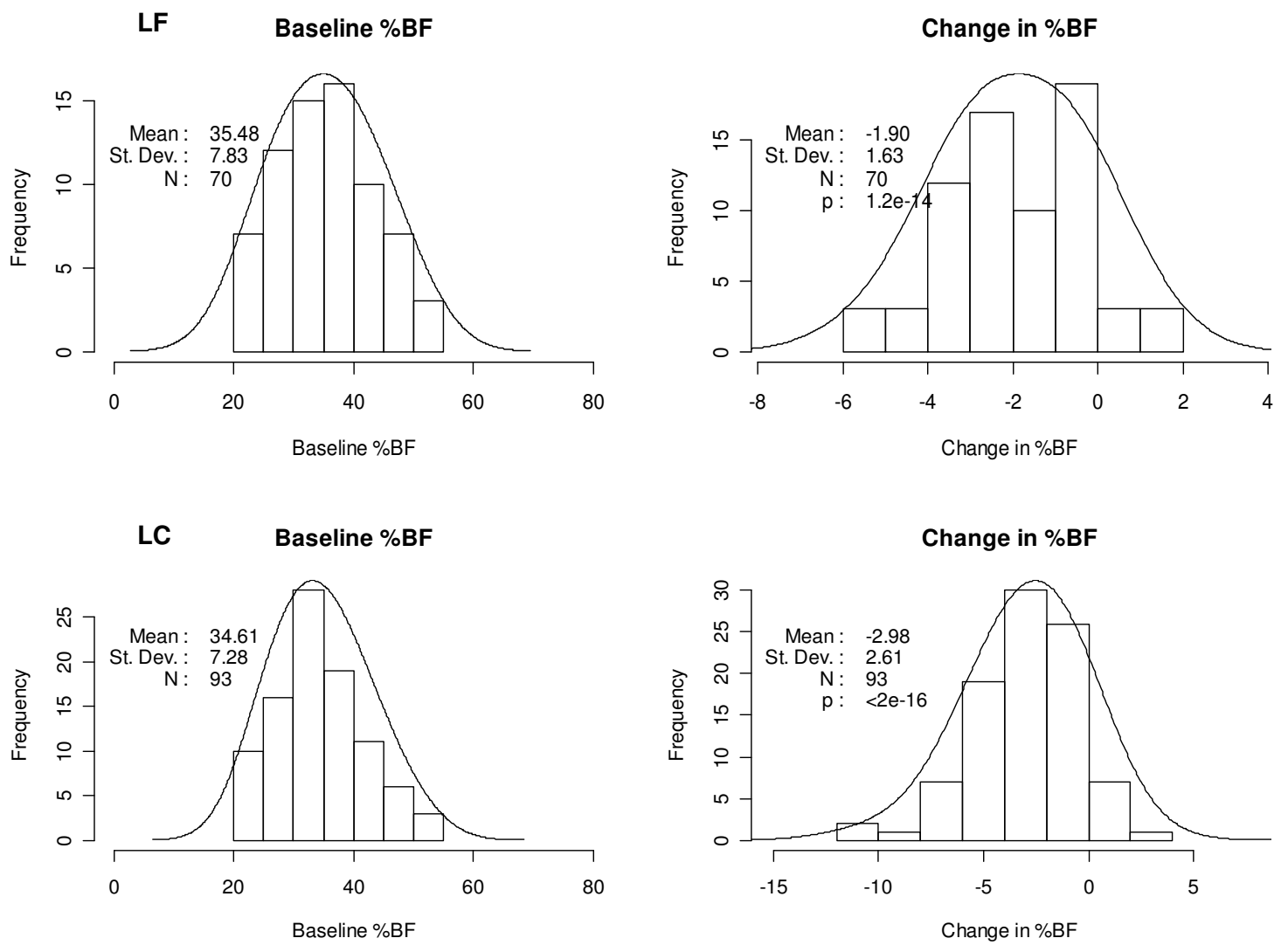

\section{Figure I}

Distribution of baseline and change in percent body fat for LF (top) and LC (bottom) groups. The vertical axes (Frequency) indicates the number of patients observed within a given $10 \%$ interval up to $60 \%$ (baseline, left panels) or within a given $2 \%$ or $5 \%$ interval (change, right panels) on the horizontal axes. Genotyping was not completed in 3 LF subjects and 7 LC subjects.

that is less than $-5 \%$, and the minor allele is completely absent among subjects with subtle change in $\Delta \% \mathrm{BF}$ (i.e., no loss of relative fat). A similar pattern is seen with the GYS2 SNP rs1478290. These two SNPs are considered reactive markers. The third panel shows the RARB SNP rs322695 response. The minor allele shows a higher frequency in the subject with little response in $\Delta \% \mathrm{BF}$, indi-

Table 6: Significance levels of gene SNPs associated with \% body fat change profiles for carbohydrate-restricted (LC) and fat-restricted (LF) diet treatments.

\begin{tabular}{|c|c|c|c|c|c|c|c|c|}
\hline \multirow[b]{2}{*}{ Area } & \multicolumn{2}{|c|}{ Marker } & \multicolumn{2}{|c|}{ P-value } & \multicolumn{2}{|c|}{ Coefficient } & \multicolumn{2}{|c|}{ FDR } \\
\hline & SNP & Gene & LF & LC & LF & LC & LF & LC \\
\hline \multirow[t]{3}{*}{ Food Intake } & rsI80II05 & HNMT & 0.941 & 0.028 & -0.03 & -2.03 & 0.960 & 0.368 \\
\hline & rs 12691940 & HNMT & 0.002 & 0.755 & 0.89 & -0.12 & $0.04 I$ & 0.974 \\
\hline & rs|46827| & NPY & 0.049 & 0.181 & -0.89 & -0.90 & 0.321 & 0.974 \\
\hline \multirow[t]{4}{*}{ Energy Homeostasis } & rs 1478290 & GYS2 & 0.038 & 0.009 & -0.60 & -0.86 & 0.321 & 0.209 \\
\hline & rs2838549 & PFKL & 0.002 & 0.902 & 1.37 & -0.10 & $0.04 I$ & 0.974 \\
\hline & rs3762272 & PKLR & 0.048 & 0.282 & -2.24 & -0.60 & 0.321 & 0.974 \\
\hline & rs322695 & RARB & 0.0001 & 0.012 & 1.29 & 1.03 & 0.005 & 0.209 \\
\hline \multirow[t]{3}{*}{ Adipocyte Regulation } & rs2058II2 & ADIPOR2 & 0.044 & 0.141 & -0.89 & -0.78 & 0.321 & 0.974 \\
\hline & rs5950584 & AGTR2 & 0.507 & 0.0001 & -0.77 & -3.31 & 0.732 & 0.021 \\
\hline & rs43940I & APOE & 0.036 & 0.691 & -0.74 & -0.15 & 0.321 & 0.974 \\
\hline
\end{tabular}

Abbreviations: Coefficient: linear regression coefficient; FDR: false discovery rate $p$ value, with those in bold type significant at $\alpha \leq 0.05$. 

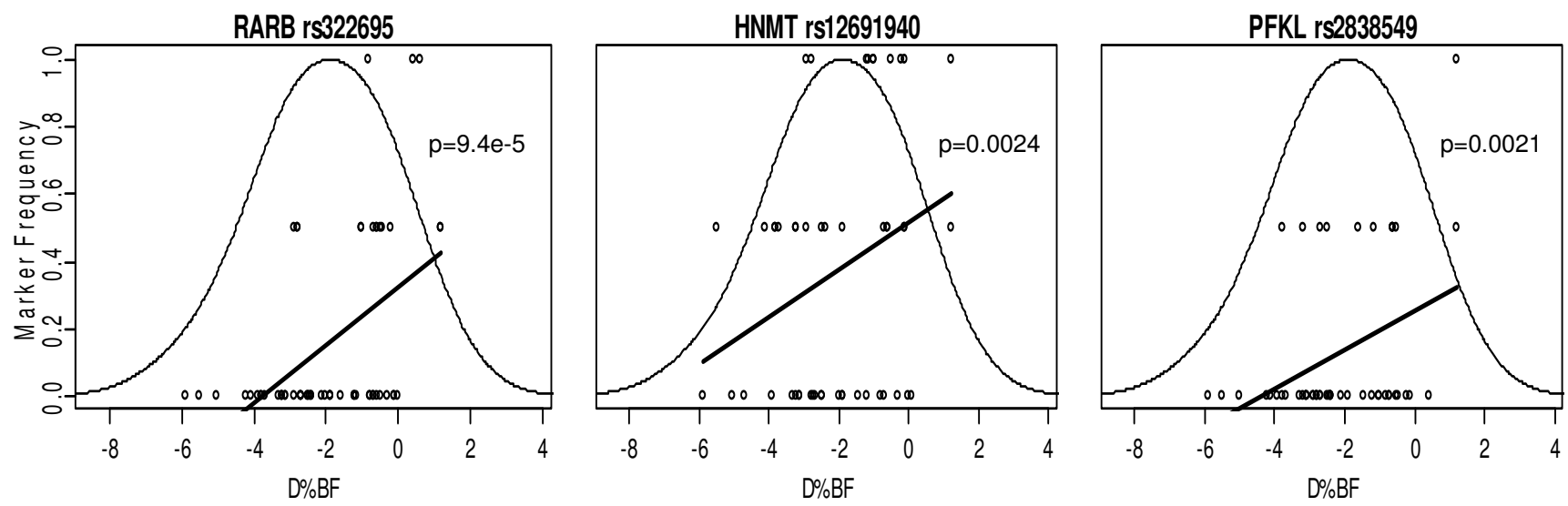

Figure 2

Physiogenomic representation of the most significant genetic associations found in the low fat diet group. Individual patient genotypes (circles) of each SNP are overlaid on the distribution of $\Delta \% \mathrm{BF}$ (thin line). Each circle represents a patient, with the horizontal axis specifying the $\Delta \% \mathrm{BF}$, and the vertical axis the carrier status for the minor allele: bottom, non-carriers; middle, single-carriers; top, double-carriers. A LOESS fit of the allele frequency (thick line) as a function of $\Delta \% B F$ is shown. The ordinate is labeled for the marker frequency (thick line) of the SNP denoted at the top of each panel. The ordinate scale is the same in all three panels. The ordinate scales for the genotypes (circles) and $\Delta \% B F$ distribution (thin line) are not shown. The abscissa is labeled for $\Delta \% \mathrm{BF}$ in each panel. The abscissa scale is the same in all three panels and applies identically to marker frequency, genotypes, and $\Delta \% \mathrm{BF}$ distribution.

cating that the RARB SNP rs322695 is a torpid marker of responsiveness to $\mathrm{LC}$ diet also.

\section{Discussion}

The present study shows that genetic associations with changes in $\Delta \% \mathrm{BF}$ established for genes in pathways encompassing food intake, energy homeostasis, and adipocyte regulation occur in part through common pathways, and in part through different pathways that may differentiate low fat (LF) and low carbohydrate (LC) restriction. For both diets, $\Delta \% \mathrm{BF}$ profiles assessed using DXA were affected by an intergenic SNP upstream of $R A R B$ (rs322695), suggesting that $R A R B$ is involved in a fat loss pathway common to both diets. In contrast, strong diet-specific associations were also found for a promoter region SNP in AGTR2 (rs5950584) through LC and PFKL through LF, suggesting that there are separate mechanisms for fat loss under the LF and LC diets.
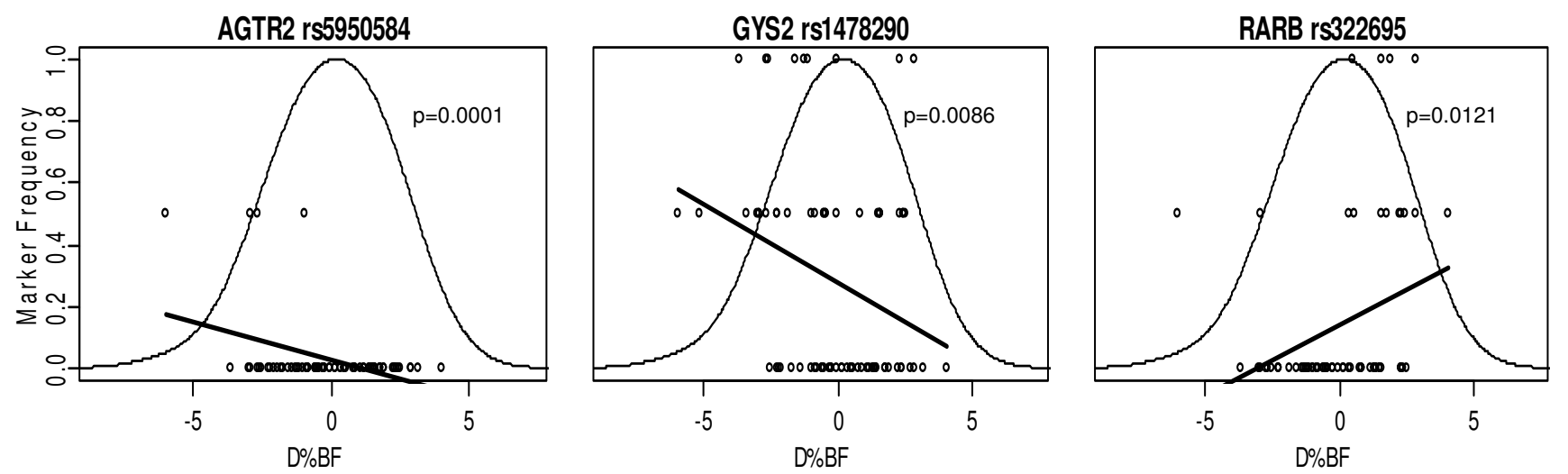

Figure 3

Physiogenomic representation of the most significant genetic associations found in the low carbohydrate group. See Figure 2 legend for details regarding individual patient genotypes (circles), the distribution of $\Delta \% B F$ (thin line), and the LOESS fit of the allele frequency (thick line) as a function of $\Delta \% \mathrm{BF}$. 


\section{Physiogenomic associations common to both LF and LC} We observed a significant relationship between the RARB SNP rs322695 and change in relative fat to both diets after accounting for nongenetic factors. The relationship was significant after correction for multiple testing in mediation of the LF $\Delta \% B F$ profiles $(\mathrm{p}<0.005)$. This observation is noteworthy in light of the putative role of the retinoic acid system in insulin resistance [60]. The RARB SNP rs322695 is found $100 \mathrm{~kb}$ upstream and $\sim 600 \mathrm{~kb}$ from the adjacent THR (thyroid hormone receptor) gene. We have attributed this SNP to RARB because it is the next gene downstream, and regulatory elements such as enhancers have been found several hundred kb from their transcription start sites. However, it cannot be excluded that the SNP effect may be unrelated to RARB protein expression, and rather involve an as yet uncharacterized protein or non-coding RNA [61]. We are unaware of other polymorphisms in the region or near $R A R B$ that are related to body weight or fat regulation in humans and believe this finding to be novel.

The widespread genomic distribution of retinoic acid response elements (RARE) suggests participation in many physiological pathways [62-64]. Recently Morgan et al. [40] described a neural hypothesis for regulation of annual cycles of body fattening in animals in which changes in the expression of RAR in the arcuate nucleus of the brain were noted. Vitamin A deficiency preferentially decreases hepatic $R A R B$ expression [65], and regulates hepatic glucose metabolic enzymes [66]. Given that hepatic enzyme energy regulation occurs in part through $R A R B$ signaling, the present finding allows the hypothesis that the rs322695 variant affects such regulation.

\section{Physiogenomic associations specific to $\mathbf{L F}$}

In addition to the RARB gene, LF $\triangle \% B F$ profiles had relationships through PFKL and one SNP in HNMT not found with LC. The HNMT SNP rs3100722, found at intron 2, and the PFKL SNP rs2838549, located in intron 8, showed significant relationships $(\mathrm{p}<0.041)$ after correction for multiple tests) second in strength only to the RARB gene. The HNMT inhibitor metoprine suppresses feeding in mice [67]. The present finding enables us to hypothesize a role for HNMT in the regulation of food intake. Hepatic phosphofructokinase, a key regulatory enzyme for glycolysis encoded by $P F K L$, is responsive to macronutrient changes [68] and is regulated by Vitamin A [66]. Genetic loci near PFKL have been associated with bipolar affective disorder [69], but to our knowledge, no SNPs are known to modulate diet response.

\section{Physiogenomic associations specific to LC}

The strongest association ( $\mathrm{p}<0.003$, after correction for multiple tests) was found in the LC group with SNP rs5950584 in the angiotensin II receptor, type 2 (AGTR2).
This SNP is found $\sim 4.5 \mathrm{~kb}$ upstream in the promoter region. The AGTR2 gene has a metabolic role that is in contrast to the vascular role of the angiotensin II type 1 receptor (AGTR1 gene), which we previously found linked to statin-associated elevations in serum creatine kinase [17]. Humans and mice express AGTR2 in muscle and adipose tissue, and evidence supports the existence of a functional renin angiotensin II system within adipose tissue [70]. Mice lacking the AGTR2 receptor are resistant to the adipocyte hypertrophy and muscle cell insulin resistance induced by high fat, hypercaloric feeding [71]. AGTR2dependent angiotensin II signaling thus could account for LC unresponsiveness [71]. AGTR2 polymorphisms were reported to modulate left ventricular mass, through the polymorphism known as G1675A (rs1403543) in a European population [72], and the T-A combination derived from G/T rs5193 and G/A rs5194 SNPs in a Cantonese population [73].

In the present study, the AGTR2 SNP rs5950584 serves as a reactive marker for the $\mathrm{LC}$ diet response. The AGTR2 gene is X-linked, thus men can have only one of either the $\mathrm{T}$ (major) or the $\mathrm{G}$ (minor) allele, while women may have zero, one, or two copies of either allele. Men lost significantly more fat than women, which together with the Xlinked nature of the gene might lead to a false positive result. However, gender was highly significant in our covariate model, and the association test was performed adjusting for it, which excludes such a confounding effect.

Another association was found between LC response and the SNP rs1478290 in the GYS2 gene. The GYS2 product is glycogen synthase 2, a key regulator of hepatic glucose storage that is increased by feeding [74]. The GYS2 SNP rs 1478290 is found in the promoter region. We previously found a different GYS2 SNP, rs2306179, located in intron 5 , to be associated with body weight loss in response to LC diet [5]. The present study, conducted in a larger number of subjects, found also that a variant in the GYS2 gene is a response marker for the change in relative fat induced by LC.

\section{Differentiation of LF and LC diet responses}

The number of significant associations overall suggests a complex system through which regulation of the \%BF phenotype is accomplished. Our list of genes, which is comparable to other studies to date [15], is exploratory, not comprehensive, and is representative of food intake, energy homeostasis, and adipocyte regulation. Virtually none of the genes in the present study were examined by previous diet studies $[13,15]$. Nevertheless, the present results showed a larger number of gene associations with $\Delta \% \mathrm{BF}$ profiles in relation to the LF diet compared to the LC diet. Based simply on the numbers of genes found to be significantly associated, we infer that the low fat diet 
utilizes a greater number of signal inputs into the regulation of relative body fat compared to the low carbohydrate diet. Even after the most stringent correction for multiple testing, RARB remained significantly associated with LF $\triangle \% \mathrm{BF}$ and AGTR2 remained associated with LC $\Delta \% \mathrm{BF}$.

Our findings run counter to those of a recent study [15] that reported no significant SNP associations with changes in BMI following carbohydrate or fat restriction despite using large cohorts. Methodological differences between the studies are worth noting. The present study used DXA to precisely assess $\triangle \% B F$ as opposed to relying on BMI. Second, different genes were studied. Here, the selection of genes was designed to reflect $\Delta \% \mathrm{BF}$ phenotype variability. In contrast, the SNPs examined by Sorenson et al. [15] were those demonstrated in previous reports to affect obesity and not diet response per se. Macronutrient compositions of the intervention diets were quite dichotomous in the present study, especially for carbohydrate ( $12 \%$ and $57 \%$ of total energy as carbohydrate in the LC and LF arms, respectively, in the present study; vs. $42 \%$ and $57 \%$, respectively, in the study of Sorenson et al. [15]). We believe a greater imbalance in the macronutrient combination increases the strength of the dietary stimuli, which accentuates differences in the physiological signal intensities associated with each diet, increasing the chances for detection of physiogenomic relationships.

\section{Clinical implication}

The prevention and treatment of obesity could be more efficient if dietary recommendations were carried out based on knowledge of innate individual characteristics that are genetically predictable. Moreover, adherence to dietary advice may increase when the advice is personalized. DNA-guided regimens allow healthcare providers to tailor therapies based on individual patient characteristics, rather than the average diet responses applied in longitudinal studies $[3,75]$. A dietary treatment with a higher average chance for success, for example, may be desirable for those patients who inherited an ensemble of DNA markers with the most responsive factors and the least torpid factors for it. We interpret the coefficients associated with each significant gene marker in Table 4 as either having responsive or torpid effects to facilitate fat loss. The ability to match a diet regimen's genetic "contour" with the DNA profile of an individual patient marks the beginning of high-resolution personalized nutritional medicine for the treatment and prevention of obesity.

\section{Limitations}

The number of subjects studied, the list of genes analyzed, and in some cases the frequency of the minor allele in SNPs of interest, were relatively small. Thus the results will need to be validated before clinical application. Neverthe- less, the RARB and AGTR2 results are clearly significant even when fully and most conservatively corrected for multiple comparisons. The p-values were confirmed by non-parametric permutation analysis, excluding non-normal distribution as a source of false positives. In addition, the RARB result was found in the LF group and independently confirmed in the LC group. Although we assessed only a small sample of SNPs in the genome, this study included 53 SNPs from 28 genes representing a larger ensemble of genetic probes than other published diet studies. The data for the present study were compiled from a series of studies in whom the majority of subjects were of European ancestry. We lack power to detect ethnogeographic associations or confounding effects. We did not consider men and women separately but accounted for the effect of gender through its use as a covariate. Future studies investigating a sex difference might be useful. Finally, both diets were hypocaloric. It is possible that the genes shown to exert their effects through both diets, actually do so through the commonality of caloric restriction.

\section{Authors' contributions}

RLS drafted the manuscript. JSV conceived of the study, designed and executed many of the diet restriction studies that supplied DNA, and helped draft the manuscript. AW participated in the design of the study, oversaw the genetic analyses, and performed the statistical analysis. MK performed the molecular genetic analyses. MLF participated in the design of the study and conducted some of the diet restriction studies that supplied DNA samples. WK participated in the design and coordination of diet restriction studies that supplied DNA and phenotype information. GR participated in the study design, provided oversight for genetic analyses and helped to draft the manuscript. All authors read and approved the final manuscript.

\section{Acknowledgements}

This research was funded by grants from the University of Connecticut Center for Science \& Technology Commercialization and by Genomas internal research and development funds.

\section{References}

I. Volek J, Sharman M, Gomez A, Judelson D, Rubin M, Watson G, Sokmen B, Silvestre R, French D, Kraemer W: Comparison of energyrestricted very low-carbohydrate and low-fat diets on weight loss and body composition in overweight men and women. Nutr Metab (Lond) 2004, I: 13.

2. Krauss RM, Blanche PJ, Rawlings RS, Fernstrom HS, Williams PT: Separate effects of reduced carbohydrate intake and weight loss on atherogenic dyslipidemia. Am J Clin Nutr 2006, 83:1025-103I.

3. Gardner CD, Kiazand A, Alhassan S, Kim S, Stafford RS, Balise RR, Kraemer HC, King AC: Comparison of the Atkins, Zone, Ornish, and LEARN diets for change in weight and related risk factors among overweight premenopausal women: the A TO Z Weight Loss Study: a randomized trial. JAMA 2007, 297:969-977.

4. Foster GD, Wyatt HR, Hill JO, McGuckin BG, Brill C, Mohammed BS, Szapary PO, Rader DJ, Edman JS, Klein S: A randomized trial of a 
low-carbohydrate diet for obesity. N Engl J Med 2003 , 348:2082-2090

5. Ruaño G, Windemuth $A$, Kocherla M, Holford T, Fernandez ML, Forsythe CE, Wood RJ, Kraemer WJ, Volek JS: Physiogenomic analysis of weight loss induced by dietary carbohydrate restriction. Nutr Metab (Lond) 2006, 3:20.

6. Krieger JW, Sitren HS, Daniels MJ, Langkamp-Henken B: Effects of variation in protein and carbohydrate intake on body mass and composition during energy restriction: a meta-regression I. Am J Clin Nutr 2006, 83:260-274.

7. Harber MP, Schenk S, Barkan AL, Horowitz JF: Effects of dietary carbohydrate restriction with high protein intake on protein metabolism and the somatotropic axis. J Clin Endocrinol Metab 2005, 90:5I75-5I8I

8. Kennedy AR, Pissios P, Otu HH, Xue B, Asakura K, Furukawa N, Marino FE, Liu FF, Kahn BB, Libermann TA, Maratos-Flier E: A High Fat, Ketogenic Diet, Induces a Unique Metabolic State in Mice. Am J Physiol Endocrinol Metab 2007, 292:EI724-EI739.

9. Kallio P, Kolehmainen M, Laaksonen DE, Kekalainen J, Salopuro T, Sivenius K, Pulkkinen L, Mykkanen HM, Niskanen L, Uusitupa M, Poutanen KS: Dietary carbohydrate modification induces alterations in gene expression in abdominal subcutaneous adipose tissue in persons with the metabolic syndrome: the FUNGENUT Study. Am J Clin Nutr 2007, 85:|4| 7- 1427.

10. Eckel RH, Hernandez TL, Bell ML, Weil KM, Shepard TY, Grunwald GK, Sharp TA, Francis CC, Hill JO: Carbohydrate balance predicts weight and fat gain in adults. Am J Clin Nutr 2006, 83:803-808.

II. Zurlo F, Lillioja S, Esposito-Del Puente A, Nyomba BL, Raz I, Saad MF, Swinburn BA, Knowler WC, Bogardus C, Ravussin E: Low ratio of fat to carbohydrate oxidation as predictor of weight gain: study of 24-h RQ. Am J Physiol 1990, 259:E650-E657.

12. Thomas CD, Peters JC, Reed GW, Abumrad NN, Sun M, Hill JO: Nutrient balance and energy expenditure during ad libitum feeding of high-fat and high-carbohydrate diets in humans. Am J Clin Nutr 1992, 55:934-942.

13. Rankinen T, Zuberi A, Chagnon YC, Weisnagel SJ, Argyropoulos G, Walts B, Perusse L, Bouchard C: The human obesity gene map: the 2005 update. Obesity (Silver Spring) 2006, 14:529-644.

14. Moreno-Aliaga MJ, Santos JL, Marti A, Martinez JA: Does weight loss prognosis depend on genetic make-up? Obes Rev 2005, 6:155-168.

15. Sorensen TI, Boutin P, Taylor MA, Larsen LH, Verdich C, Petersen L Holst C, Echwald SM, Dina C, Toubro S, Petersen M, Polak J, Clement K, Martinez JA, Langin D, Oppert JM, Stich V, Macdonald I, Arner P, Saris WH, Pedersen O, Astrup A, Froguel P: Genetic Polymorphisms and Weight Loss in Obesity: A Randomised Trial of Hypo-Energetic High- versus Low-Fat Diets. PLoS Clin Trials 2006, I:el2.

16. Ruaño G, Windemuth A, Holford TR: Physiogenomics: Integrating Systems Engineering and Nanotechnology for Personalized Medicine. In Tissue Engineering and Artificial Organs Volume 28. 3rd edition. Edited by: Bronzino JD. Boca Raton, CRC: Taylor and Francis; 2006:28-I-28-9.

17. Ruaño G, Thompson PD, Windemuth A, Smith A, Kocherla M, Holford TR, Seip R, Wu AH: Physiogenomic analysis links serum creatine kinase activities during statin therapy to vascular smooth muscle homeostasis. Pharmacogenomics 2005 6:865-872.

18. Ruaño G, Goethe JW, Caley C, Woolley S, Holford TR, Kocherla M, Windemuth A, Leon J: Physiogenomic comparison of weight profiles of olanzapine- and risperidone-treated patients. Mol Psychiatry 2007, I2:474-482.

19. Ruaño G, Thompson PD, Windemuth A, Seip RL, Dande A, Sarokin A, Kocherla M, Smith A, Holford TR, Wu AH: Physiogenomic Association of Statin-Related Myalgia to Serotonin Receptors. Muscle and Nerve 2007, 36:329-335.

20. Paradisi G, Smith L, Burtner C, Leaming R, Garvey WT, Hook G, Johnson A, Cronin J, Steinberg HO, Baron AD: Dual energy X-ray absorptiometry assessment of fat mass distribution and its association with the insulin resistance syndrome. Diabetes Care 1999, 22:1310-1317.

21. Glickman SG, Marn CS, Supiano MA, Dengel DR: Validity and reliability of dual-energy $X$-ray absorptiometry for the assessment of abdominal adiposity. J Appl Physiol 2004, 97:509-5 I 4
22. Volek JS, Sharman MJ, Gomez AL, Scheett TP, Kraemer W]: An isoenergetic very low carbohydrate diet improves serum HDL cholesterol and triacylglycerol concentrations, the total cholesterol to HDL cholesterol ratio and postprandial pipemic responses compared with a low fat diet in normal weight, normolipidemic women. J Nutr 2003, I33:2756-276I.

23. Volek JS, Sharman MJ, Love DM, Avery NG, Gomez AL, Scheett TP, Kraemer WJ: Body composition and hormonal responses to a carbohydrate-restricted diet. Metabolism 2002, 5 I:864-870.

24. Sharman MJ, Kraemer WJ, Love DM, Avery NG, Gomez AL, Scheett TP, Volek JS: A ketogenic diet favorably affects serum biomarkers for cardiovascular disease in normal-weight men. J Nutr 2002, I32:1879-1885.

25. Wood RJ, Volek JS, Liu Y, Shachter NS, Contois JH, Fernandez ML: Carbohydrate restriction alters lipoprotein metabolism by modifying VLDL, LDL, and HDL subfraction distribution and size in overweight men. J Nutr 2006, 136:384-389.

26. Leibowitz SF: Overconsumption of dietary fat and alcohol: Mechanisms involving lipids and hypothalamic peptides. Physiol Behav 2007:5I3-52I.

27. Shaw AM, Irani BG, Moore MC, Haskell-Luevano C, Millard WJ: Ghrelin-induced food intake and growth hormone secretion are altered in melanocortin 3 and $\mathbf{4}$ receptor knockout mice. Peptides 2005, 26:1720-I727.

28. HNMT, histamine N-methyl transferase, function 2007 [http:/ /www.ncbi.nlm.nih.gov/entrez/dispomim.cgi?id=605238].

29. LIPF, Gastic Lipase, function 2007 [http://www.ncbi.nlm.nih.gov/ entrez/dispomim.cgi?id=601980].

30. Adrian TE, Ferri GL, Bacarese-Hamilton AJ, FuessI HS, Polak JM, Bloom SR: Human distribution and release of a putative new gut hormone, peptide YY. Gastroenterology 1985, 89: 1070-1077.

31. Ingenhoven N, Beck-Sickinger AG: Molecular characterization of the ligand-receptor interaction of neuropeptide Y. Curr Med Chem 1999, 6: 1055-1066.

32. Faroogi S: Treating obesity: does antagonism of NPY fit the bill? Cell Metab 2006, 4:260-262

33. Erondu N, Wadden T, Gantz I, Musser B, Nguyen AM, Bays H, Bray G, O'Neil PM, Basdevant A, Kaufman KD, Heymsfield SB, Amatruda IM: Effect of NPY5R antagonist MK-0557 on weight regain after very-low-calorie diet-induced weight loss. Obesity (Silver Spring) 2007, I 5:895-905.

34. Balthasar N: Genetic dissection of neuronal pathways controlling energy homeostasis. Obesity (Silver Spring) 2006, I4 Suppl 5:222S-227S

35. Butler AA: The melanocortin system and energy balance. Peptides 2006, 27:28I-290.

36. Tso P, Liu M: Apolipoprotein A-IV, food intake, and obesity. Physiol Behav 2004, 83:63I-643.

37. Salway JG: Metabolism at a glance 2nd edition. Oxford, Blackwell Science, Ltd.; 1999.

38. PFKL, phosphofructokinase, liver, function 2007 [http:// www.ncbi.nlm.nih.gov/entrez/dispomim.cgi?id=17|860].

39. PFKM, phosphofructokinase, muscle, function 2007 [http:// www.ncbi.nlm.nih.gov/entrez/dispomim.cgi?id=61068I].

40. Morgan PJ, Ross AW, Mercer JG, Barrett P: What can we learn from seasonal animals about the regulation of energy balance? Prog Brain Res 2006, I53:325-337.

41. Redonnet A, Groubet R, Noel-Suberville C, Bonilla S, Martinez A, Higueret $P$ : Exposure to an obesity-inducing diet early affects the pattern of expression of peroxisome proliferator, retinoic acid, and triiodothyronine nuclear receptors in the rat. Metabolism 2001, 50:1161-1167.

42. Xiao CW, Mei J, Huang W, Wood C, L'abbe MR, Gilani GS, Cooke GM, Curran IH: Dietary soy protein isolate modifies hepatic retinoic acid receptor-beta proteins and inhibits their DNA binding activity in rats. I Nutr 2007, I 37: I-6.

43. Zorad S, Fickova M, Zelezna B, Macho L, Kral JG: The role of angiotensin II and its receptors in regulation of adipose tissue metabolism and cellularity. Gen Physiol Biophys 1995, 1 4:383-391.

44. Storgaard H, Poulsen P, Ling C, Groop L, Vaag AA: Relationships of plasma adiponectin level and adiponectin receptors $I$ and 2 gene expression to insulin sensitivity and glucose and fat metabolism in monozygotic and dizygotic twins. J Clin Endocrinol Metab 2007, 92:2835-2839. 
45. Huang ZH, Luque RM, Kineman RD, Mazzone T: Nutritional regulation of adipose tissue apolipoprotein $\mathbf{E}$ expression. Am J Physiol Endocrinol Metab 2007, 293:E203-E209.

46. Jiang XC, Moulin P, Quinet E, Goldberg IJ, Yacoub LK, Agellon LB, Compton D, Schnitzer-Polokoff R, Tall AR: Mammalian adipose tissue and muscle are major sources of lipid transfer protein mRNA. J Biol Chem 199I, 266:463I-4639.

47. Drayna D, Jarnagin AS, McLean J, Henzel W, Kohr W, Fielding C, Lawn R: Cloning and sequencing of human cholesteryl ester transfer protein cDNA. Nature 1987, 327:632-634.

48. Luo Y, Tall AR: Sterol upregulation of human CETP expression in vitro and in transgenic mice by an LXR element. J Clin Invest 2000, 105:513-520.

49. Wolf G: Insulin resistance and obesity: resistin, a hormone secreted by adipose tissue. Nutr Rev 2004, 62:389-394.

50. Fan JB, Oliphant A, Shen R, Kermani BG, Garcia F, Gunderson KL, Hansen M, Steemers F, Butler SL, Deloukas P, Galver L, Hunt S, McBride C, Bibikova M, Rubano T, Chen J, Wickham E, Doucet D, Chang W, Campbell D, Zhang B, Kruglyak S, Bentley D, Haas J, Rigault P, Zhou L, Stuelpnagel J, Chee MS: Highly parallel SNP genotyping. Cold Spring Harb Symp Quant Biol 2003, 68:69-78.

5I. Oliphant A, Barker DL, Stuelpnagel JR, Chee MS: BeadArray technology: enabling an accurate, cost-effective approach to high-throughput genotyping. Biotechniques 2002, Suppl:56-61.

52. Dalgaard P: Introductory Statistics with R New York, Springer Science + Business Media; 2002.

53. Faraway JJ: Linear Models with R Boca Raton, FL, Chapman \& Hall/CRC; 2004.

54. Maindonald J, Braun J: Data Analysis and Graphics Using R: An Examplebased Approach 2nd edition. Cambridge, Cambridge University Press; 2007.

55. Reiner A, Yekutieli D, Benjamini Y: Identifying differentially expressed genes using false discovery rate controlling procedures. Bioinformatics 2003, 19:368-375.

56. Benjamini $Y$, Hochberg $Y$ : Controlling the false discovery rate: a practical and powerful approach to multiple testing. Journal of the Royal Statistical Society, Series B 1995, 57:289-300.

57. Benjamini $Y$, Hochberg $Y$ : On the adaptive control of the false discovery rate in multiple testing with independent statistics. Journal of Educational and Behavioral Statistics 2000, 25:60-83.

58. Cleveland WS, Devlin S): Locally weighted regression: an approach to regression analysis by local fitting. Journal of the Amercian Statistical Association 2007, 83:596-6I0.

59. Cleveland WS: Robust locally weighted regression and smoothing scatterplots. Journal of the Amercian Statistical Association 2007, 74:829-836.

60. Yang Q, Graham TE, Mody N, Preitner F, Peroni OD, Zabolotny JM, Kotani K, Quadro L, Kahn BB: Serum retinol binding protein 4 contributes to insulin resistance in obesity and type 2 diabetes. Nature 2005, 436:356-362.

61. Mattick JS: The functional genomics of noncoding RNA. Science 2005, 309:1527-1528.

62. Laudet V, Gronemeyer H: The nuclear receptor facts book San Diego, Academic Press; 2002.

63. Marshall H, Morrison A, Studer M, Popperl H, Krumlauf R: Retinoids and Hox genes. FASEB J 1996, 10:969-978.

64. Loudig O, Babichuk C, White J, Abu-Abed S, Mueller C, Petkovich M: Cytochrome P450RAI(CYP26) promoter: a distinct composite retinoic acid response element underlies the complex regulation of retinoic acid metabolism. Mol Endocrinol 2000, 1 4:1483-1497.

65. Shin DJ, Odom DP, Scribner KB, Ghoshal S, McGrane MM: Retinoid regulation of the phosphoenolpyruvate carboxykinase gene in liver. Mol Cell Endocrinol 2002, 195:39-54.

66. Shin DJ, McGrane MM: Vitamin A regulates genes involved in hepatic gluconeogenesis in mice: phosphoenolpyruvate carboxykinase, fructose-1,6-bisphosphatase and 6-phosphofructo-2-kinase/fructose-2,6-bisphosphatase. J Nutr 1997, I 27: $1274-1278$.

67. Lecklin A. Tuomisto L, MacDonald E: Metoprine, an inhibitor of histamine N-methyltransferase but not catechol-O-methyltransferase, suppresses feeding in sated and in food deprived rats. Methods Find Exp Clin Pharmacol 1995, 17:47-52.

68. Brooks SP, Lampi BJ: Time course of enzyme changes after a switch from a high-fat to a low-fat diet. Comp Biochem Physiol B Biochem Mol Biol 1997, I I 8:359-365.
69. Liu J, Juo SH, Terwilliger JD, Grunn A, Tong X, Brito M, Loth JE, Kanyas K, Lerer B, Endicott J, Penchaszadeh G, Gilliam TC, Baron M: A follow-up linkage study supports evidence for a bipolar affective disorder locus on chromosome 2 Iq22. Am J Med Genet 200I, 105: 189-194.

70. Engeli S, Gorzelniak K, Kreutz R, Runkel N, Distler A, Sharma AM: Co-expression of renin-angiotensin system genes in human adipose tissue. J Hypertens 1999, 17:555-560.

7I. Yvan-Charvet L, Even P, Bloch-Faure M, Guerre-Millo M, MoustaidMoussa N, Ferre $P$, Quignard-Boulange A: Deletion of the angiotensin type 2 receptor (AT2R) reduces adipose cell size and protects from diet-induced obesity and insulin resistance. Diabetes 2005, 54:991-999.

72. Kuznetsova T, Staessen JA, Thijs L, Kunath C, Olszanecka A, Ryabikov A, Tikhonoff V, Stolarz K, Bianchi G, Casiglia E, Fagard R, Brand-Herrmann SM, Kawecka-Jaszcz K, Malyutina S, Nikitin Y, Brand E: Left ventricular mass in relation to genetic variation in angiotensin II receptors, renin system genes, and sodium excretion. Circulation 2004, I I 0:2644-2650.

73. Zhang $\mathrm{M}, \mathrm{Ma} \mathrm{H}, \mathrm{Wang} \mathrm{BS}$, Zhao YZ: Angiotensin II type 2 receptor gene polymorphisms and cardioprotective role in essential hypertension. Heart Vessels 2006, 21:95-101.

74. Gannon MC, Nuttall FQ: Effect of feeding, fasting, and diabetes on liver glycogen synthase activity, protein, and mRNA in rats. Diabetologia 1997, 40:758-763.

75. Ruaño G: Quo Vadis Personalized Medicine? Personalized Medicine 2004, I:I-7.
Publish with Biomed Central and every scientist can read your work free of charge

"BioMed Central will be the most significant development for disseminating the results of biomedical research in our lifetime. "

Sir Paul Nurse, Cancer Research UK

Your research papers will be:

- available free of charge to the entire biomedical community

- peer reviewed and published immediately upon acceptance

- cited in PubMed and archived on PubMed Central

- yours - you keep the copyright
BioMedcentral 